\title{
ACOUSTIC EMISSION OF ZIRCALOY-2 DURING TENSILE AND FATIGUE LOADING
}

T. E. MICHAELS

AUGUST 1968

\section{AEC RESEARCH \& DEVELOPMENT REPORT}

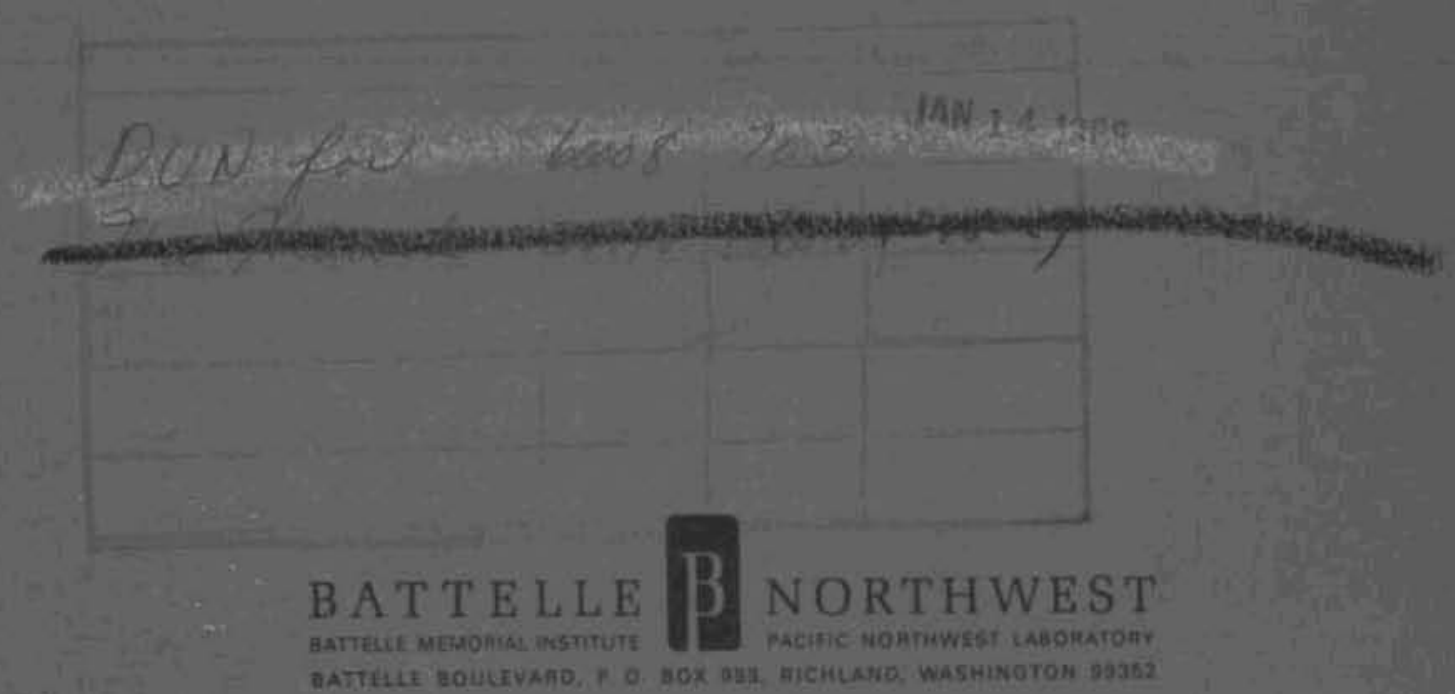




\section{LEGAL NOTICE}

This report was prepared as an account of Government sponsored work. Neither the United States, nor the Commission, nor ony person acting on beholf of the Commission.

A. Mokes any warranty or cepresentotion, expressed or implied, with respect to the accuracy, completeness, or usefulness of the information contained in this report or that the use of any infarmation, opporatus, method, or process disclosed in this repart may nof inftinge privately owned rights: or

B. Assumes any liabilities with respect to the use of, or for damages resulting from the use of any information, apparalus, method, or process disclosed in this report.

As used in the above, "person reting on behalf of the Commission" includes any employee or contractor of the Commission, or emplayee of such controctor, to the extent that such employee or contractor of the Commission. or einployee of such contractor preparas, disseminates; or provides access to; any information pursuant to his employment or contract with the Commistion, or his employment with such contractar.

\section{PACIFIC NORTHWEST LABORATORY RICHLAND, WASHINGTON \\ operated by \\ BATTELLE MEMORIAL INSTITUTE}

for the

UNITED STATES ATOMIC ENERGY COMMISSION UNDER CONTRACT AT(45-1) 1830 


\section{ERRATA}

Page 14: In Figure 10, under "Percent of Fatigue Life at Which Test Was Stopped," delete "98\%" and change "92\%" (immediately underneath) to "98\%".

Page 15: In Figure 11, under "Percent of Fatigue Life at Which Test Was Stopped," insert "98\%" midway between the second "A" and the second "B" from the top.

Page 20: In second paragraph, first sentence should read:

Results of the acoustic emission monitoring of Zircaloy-2 tensile tests showed in both the signal voltage and the number of pulses per unit of engineering strain, a pronounced peak before the $0.2 \%$ off-set yield point.

Page 23: In the caption for Figure 15, substitute the word "Fatigue" for the word "Acoustic"。 


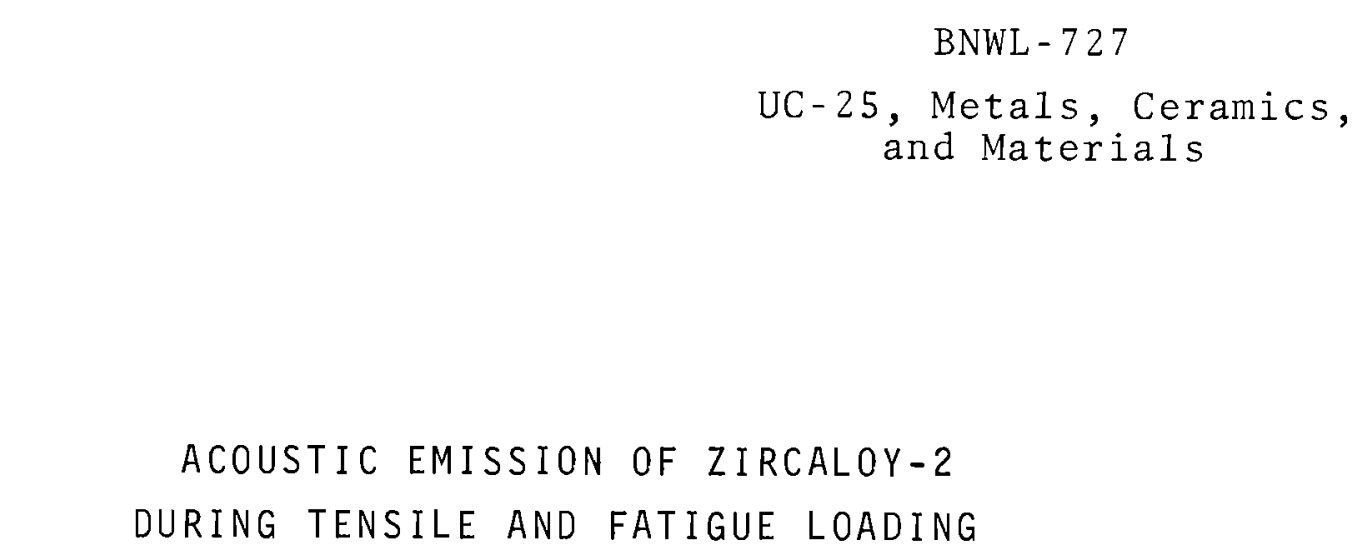

By

T. E. Michaels

Engineering Materials and Mechanics Section Engineering Development Department

August 1968

BATTELLE MEMORIAL INSTITUTE

PACIFIC NORTHWEST LABORATORY

Richland, Washington 
Printed in the United States of America Available from

Clearinghouse for Federal Scientific and Technical Information National Bureau of Standards, U.S. Department of Commerce

Springfield, Virginia 22151

Price: Printed Copy $\$ 3.00$; Microfiche $\$ 0.65$ 


\title{
ACOUSTIC EMISSION OF ZIRCALOY-2 \\ DURING TENSILE AND FATIGUE LOADING \\ T. E. Michaels
}

\begin{abstract}
The acoustic emission of Zircaloy-2 has been studied during tensile and fatigue loading at room temperature. A considerable amount of signal was received during these loading tests and metallographic evidence relating acoustic emission to deformation processes was acquired.
\end{abstract}




\section{ACOUSTIC EMISSION OF ZIRCALOY-2 \\ DURING TENSILE AND FATIGUE LOADING}

T. E. Michaels

\section{INTRODUCT ION}

This report, on the acoustic emission characteristics of Zircaloy-2 during tensile and fatigue loading, is part of a continuing effort in the utilization of acoustic emission as a laboratory tool to evaluate irradiated and unirradiated zirconium alloy pressure tubes. (1)

Metals under applied stress release energy in the form of propagating vibrational waves, and this energy is defined as acoustic emission. This energy can be monitored by coupling a vibrational pickup device to the surface of the specimen and using the received acoustic emission as a means of measuring different metal properties or conditions associated with metal deformation. Examples of such acoustic emission application would be the measurement of localized or general yielding, stress intensification factors, crack generation, crack growth, and fatigue in metallic specimens.

\section{SUMMARY AND CONCLUSIONS}

Some of the acoustic emission characteristics of Zircaloy-2 during tensile and fatigue testing have been studied over frequencies ranging from $100 \mathrm{kHz}$ to $1 \mathrm{MHz}$.

The Zircaloy-2 specimens tested in tension exhibited a pronounced acoustic emission signal peak just prior to the $0.2 \%$ offset yield point, after which the signal decreased as specimen failure was approached. The major portion of the signal is believed to be due to the initiation of dislocation movement, because the maximum in signal generation and the initiation of dislocation movement both occur before macro yielding of the specimen. 
The acoustic emission response to tensile specimen load cycling was observed to decrease markedly after the first cycle and continue to decrease with each subsequent cycle. Reloading to above any previous stress maximum resulted in a sharp increase in the amount of acoustic emission response as the previous stress maximum level was passed. This increase was seen to be continuous with the acoustic emission response curve received during the first loading to that point.

Considerably more signal was received from the fatigue specimens loaded at a $30-c y c l e / s e c$ rate than from the tensile test specimens because of the much higher strain rates involved. The monitoring instrumentation was operated at lower gain for the fatigue tests because of the increased amount of signal. The acoustic emission response received from the fatigue tests was initially high and then decreased to a stable value after approximately 10 to $25 \%$ of the fatigue 1 ife. The higher signal received during this first part of fatigue testing was believed to be related to yielding. The decay of signal with each load cycle corresponded to observations on the load cycling of the tensile specimens. Photomicrographs of specimens fatigued from 10 to $25 \%$ of fatigue life gave no evidence of gross crack movement or twinning events. The acoustic emission response appeared to remain constant over the middle range of the specimen fatigue life until immediately prior to failure. Metallographic examination indicated that a fatigue crack was initiated during this middle range of fatigue life and that the twin density gradually increased. A build-up occurred in acoustic emission response just prior to failure and was observed to be reproducible from test to test. This build-up was approximately $10 \mathrm{sec}$ in length for all cases observed. Oscilloscope traces showed the majority of these signals to be nonperiodic at a 30 cycle/sec loading frequency. 
Metallographic examination showed this portion of the fatigue life to correspond to a period of crack propagation, with much twinning evident in grains adjacent to the crack tip. The majority of signals received during the build-up prior to failure was believed to be due to the observed twinning events, the initiation of dislocation movement in the plastic zone ahead of the crack tip, and possibly some mechanical noise produced by slapping together of the crack walls with each load cycle.

\section{DISCUSSION}

MONITORING SYSTEM

The monitoring system consisted of a lead zirconate titanate peizoelectric transducer used as the pickup device, a $26 \mathrm{~dB}$ gain preamplifier, a variable gain amplifier stretcher, and a strip chart recorder. This system is shown schematically in Figure 1. The peizoelectric crystal was fluid coupled to the surface of the specimen within a few inches of the maximum stress region. The total circuit gain was set at $80 \mathrm{~dB}$ for the tensile test monitoring, and at $67 \mathrm{~dB}$ for fatigue test monitoring. The information, pulse in appearance, was received over a frequency range from $100 \mathrm{kHz}$ to $1 \mathrm{MHz}$ and was conditioned by stretching before recording to place it in the frequency response range of a strip chart recorder.

TENSILE TESTING ARRANGEMENT

The tensile specimens were machined from 0.130 in. annealed sheet of Zircaloy-2 (Figure 2). A pinned type fixture coupled the load to the tensile specimen to exclude possible generation of vibrational noise due to slippage of the specimen in a grip arrangement. All tensile tests were conducted at room temperature. 


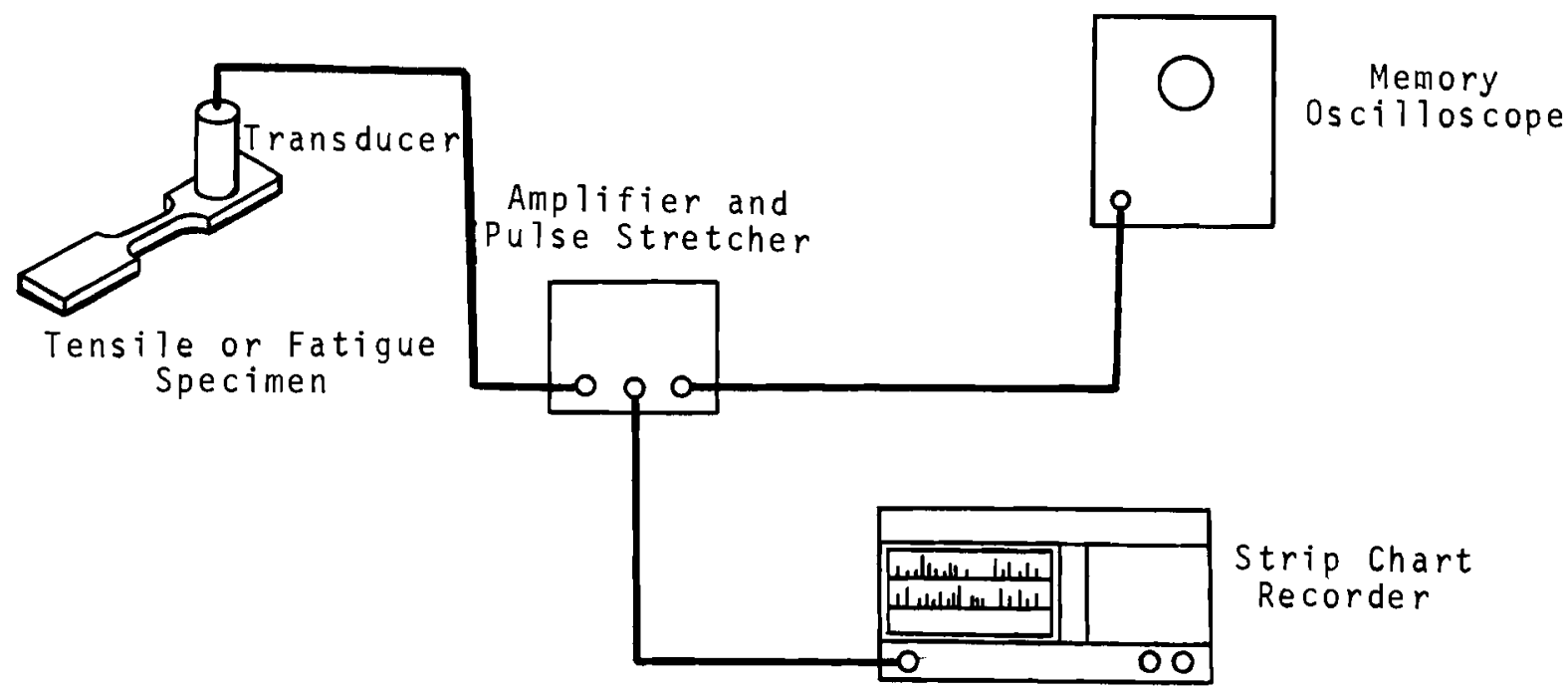

FIGURE 1. Acoustic Emission Monitoring System

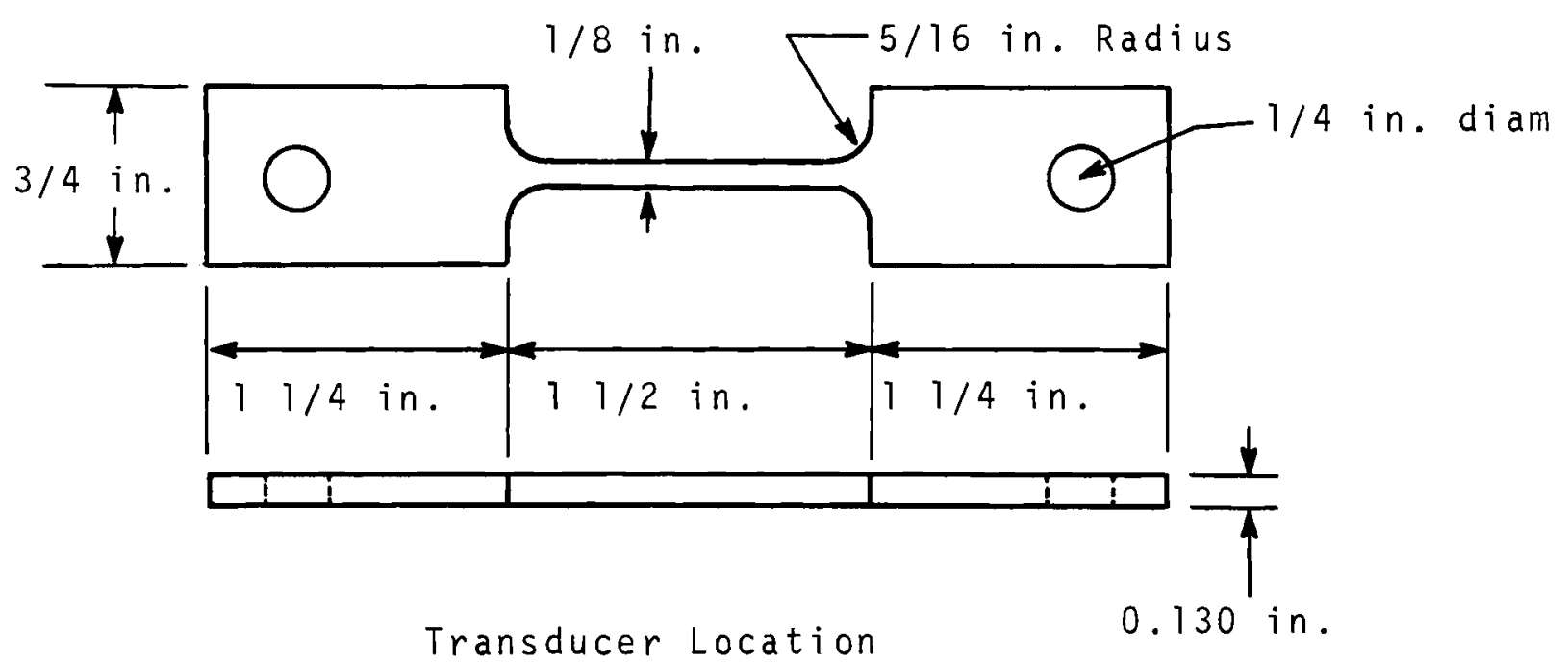

FIGURE 2. Zircaloy-2 Tensile specimen showing Transducer Location 


\section{FATIGUE TESTING ARRANGEMENT}

The cantilever beam flexure fatigue specimens were machined from $0.130 \mathrm{in}$. annealed sheet of Zircaloy-2 (Figure 3). The fatigue fixture consisted of an electromagnetic shaker coupled to the specimen to produce the required displacement. The signal from a variable frequency sine wave generator was amplified sufficiently to drive the electromagnetic shaker (Figure 4). A11 fatigue tests were conducted at room temperature.

\section{ACOUSTIC EMISSION RESULTS OF TENSILE TESTS}

Several tensile tests were conducted with the acoustic emission monitoring system in place. A few representative tests are discussed in this report. The number of pulses of information per unit of engineering strain $\frac{d n}{d \varepsilon}$, has been superimposed on an engineering stress-strain curve as determined for each of three tests conducted (Figure 5). A peak on this curve was observed for al1 specimens immediately prior to the $0.2 \%$ offset yield point. Also shown in Figure 5 is the total signal voltage per unit engineering strain $\frac{d v}{d \varepsilon}$, as superimposed on the engineering stress-strain curve determined for each specimen. A peak in the signal voltage curve is also observed immediately prior to the $0.2 \%$ offset yield point. The total acoustic emission response, i.e. both $\frac{d n}{d \varepsilon}$, and $\frac{d v}{d \varepsilon}$, is seen to decrease as the ultimate strength is approached. The curves plotted in Figure 5 represent strains to one half of the strain at failure. Although not shown, the signal in a11 cases continued to decrease as failure was approached.

The acoustic emission response has been superimposed on the engineering stress-strain curve for a specimen load cycled several times to different stress levels (Figure 6). In observing the acoustic emission response, two trends are apparent. First, upon load cycling from zero stress to a particular maximum 


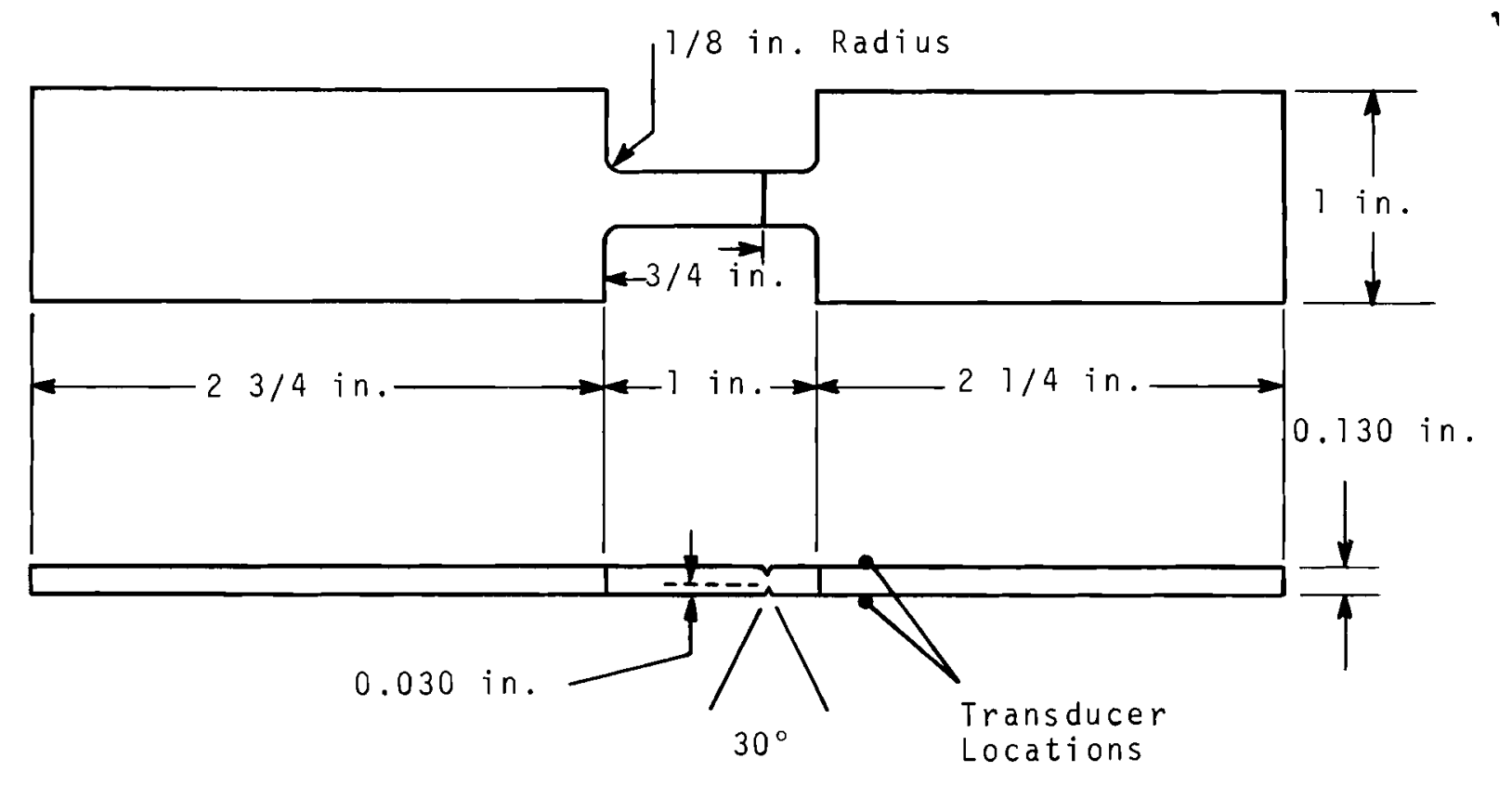

FIGURE 3. Zircaloy-2 Fatigue specimen Showing Transducer Location

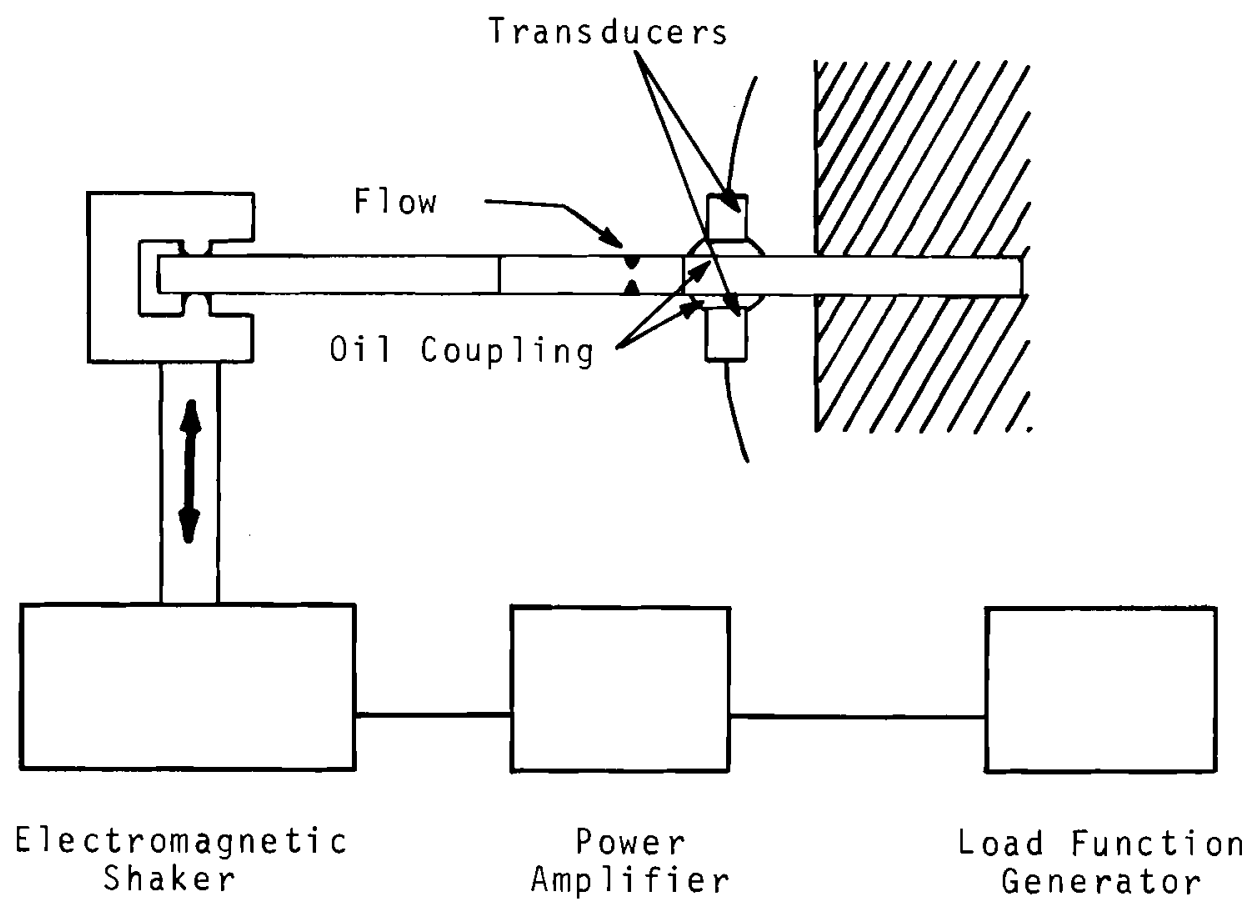

FIGURE 4. Fatigue Fixture and Electrical System 

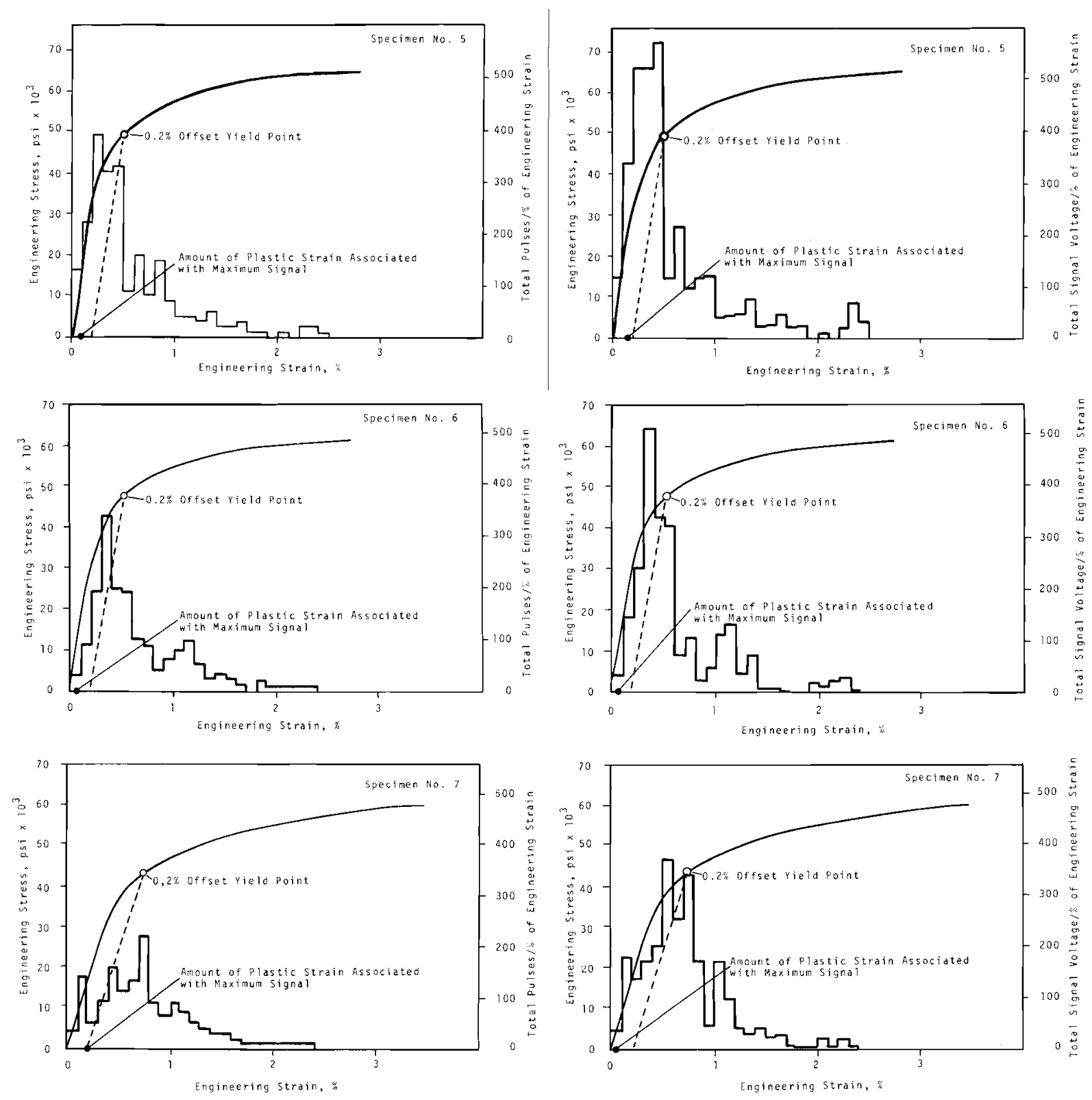

FIGURE 5. Acoustic Emission of Zircaloy-2 During Tensize Loading 

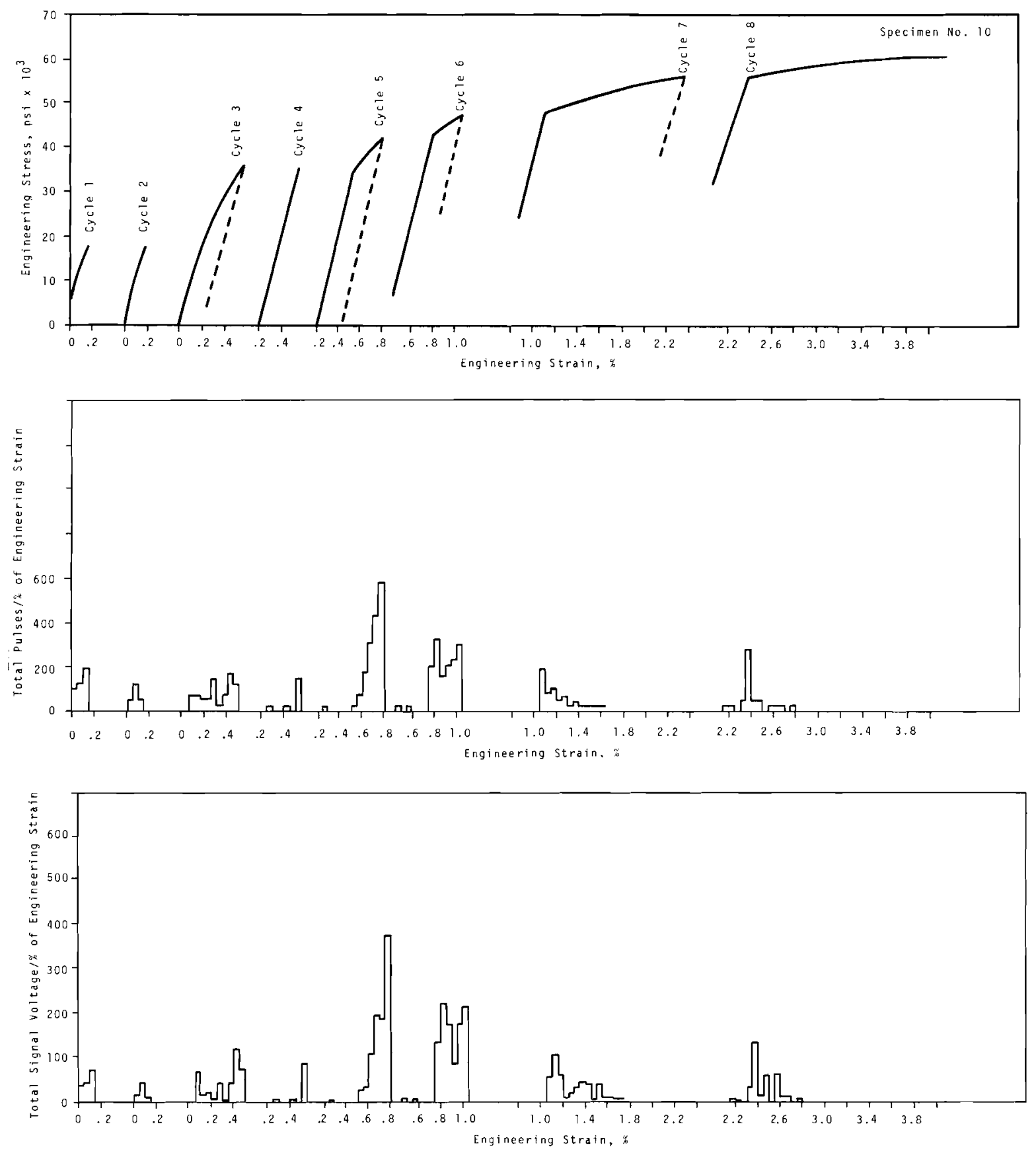

EIGURE 6. Acoustic Emission Behavior of Zircaloy-2 During Load Cycling of a Tensize specimen 
stress, the amount of acoustic emission response decreases with each cycle. This is observable in the acoustic emission response received from the first four load cycles. Second, an increase in acoustic emission response as the previous maximum stress level is passed during recycling is observable between cycles 4 and 5,5 and 6,6 and 7 , and 7 and 8 . Figure 7 is generated if the data from Figure 6 is plotted as a single stress-strain curve (omitting data obtained during recyling up to previous maximum stress levels). Again, both $\frac{d n}{d \varepsilon}$, and $\frac{d v}{d \varepsilon}$, have a pronounced maximum near the $0.2 \%$ yield point.

\section{ACOUSTIC EMISSION RESULTS OF FATIGUE TESTS}

A summary of two groups of fatigue tests is superimposed on a stress versus load cycles to failure curve in Figure 8 . The general shape of the curve was first established and data from these initial groups of tests were plotted in assuming an endurance 1 imit of approximately 23,000 psi to calibrate the stress axis. (2)

The acoustic emission data from these initial tests showed two general trends. First, the pulse rate and pulse amplitude, initially high at the start of the fatigue test, decayed to a stable value after approximately $10 \%$ of the fatigue 1 ife. Second, a build-up in the acoustic emission response was observed immediately prior to failure in all cases (Figure 9). The length of this burst of information before failure was approximately $10 \mathrm{sec}$ in all cases under these test conditions.

The second series of fatigue tests was conducted to to investigate in more detail both of these trends. A stress of $26,000 \mathrm{psi}$ was chosen for this series of tests. First, a specimen was fatigue cycled until an estimated $75 \%$ of the acoustic emission build-up immediately prior to failure was received that the test was then stopped. This point corresponded to approximately $99.5 \%$ of 

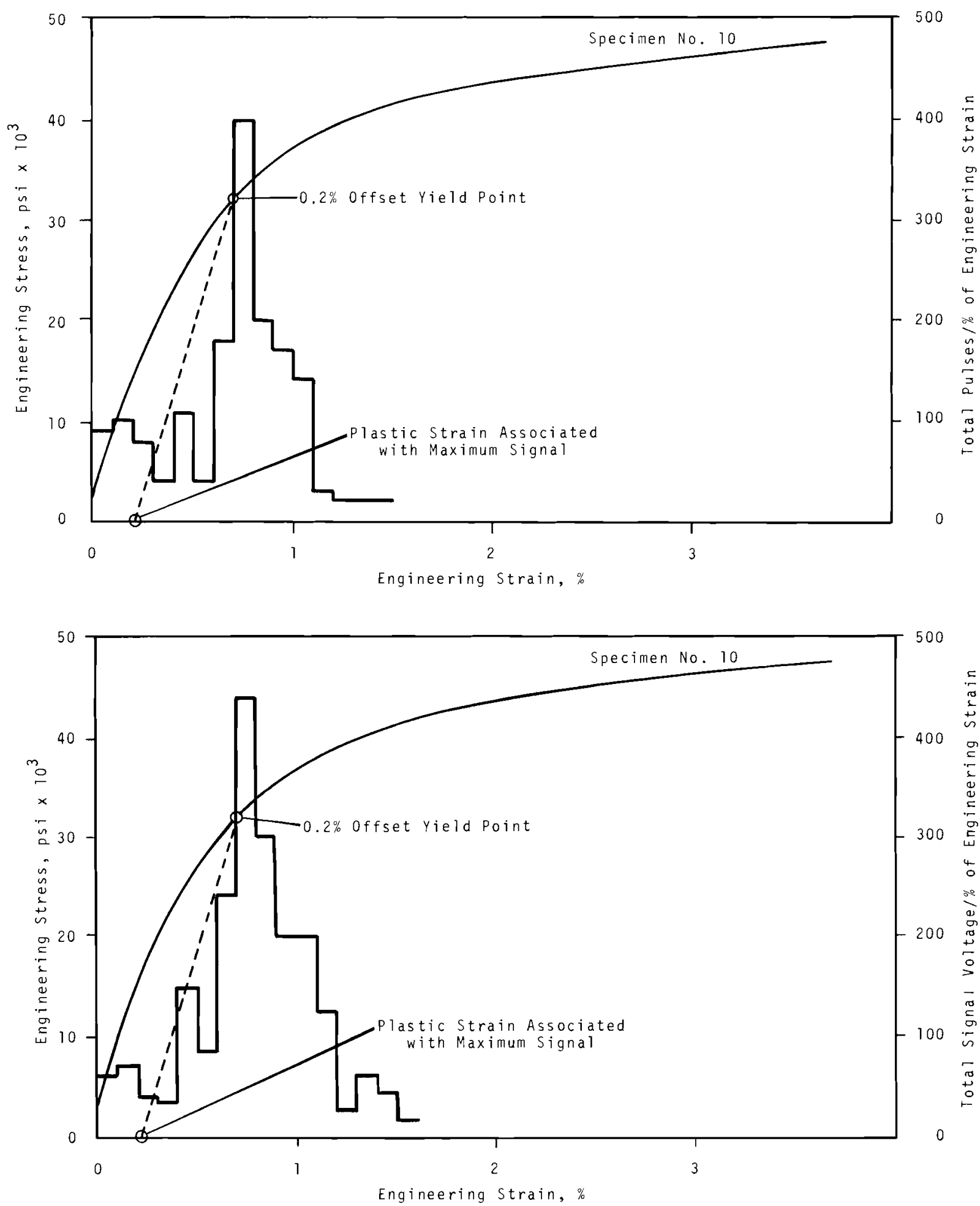

FIGURE ?. Composite Acoustic Emission Response from Load Cycled Specimen of Zircaloy-2 


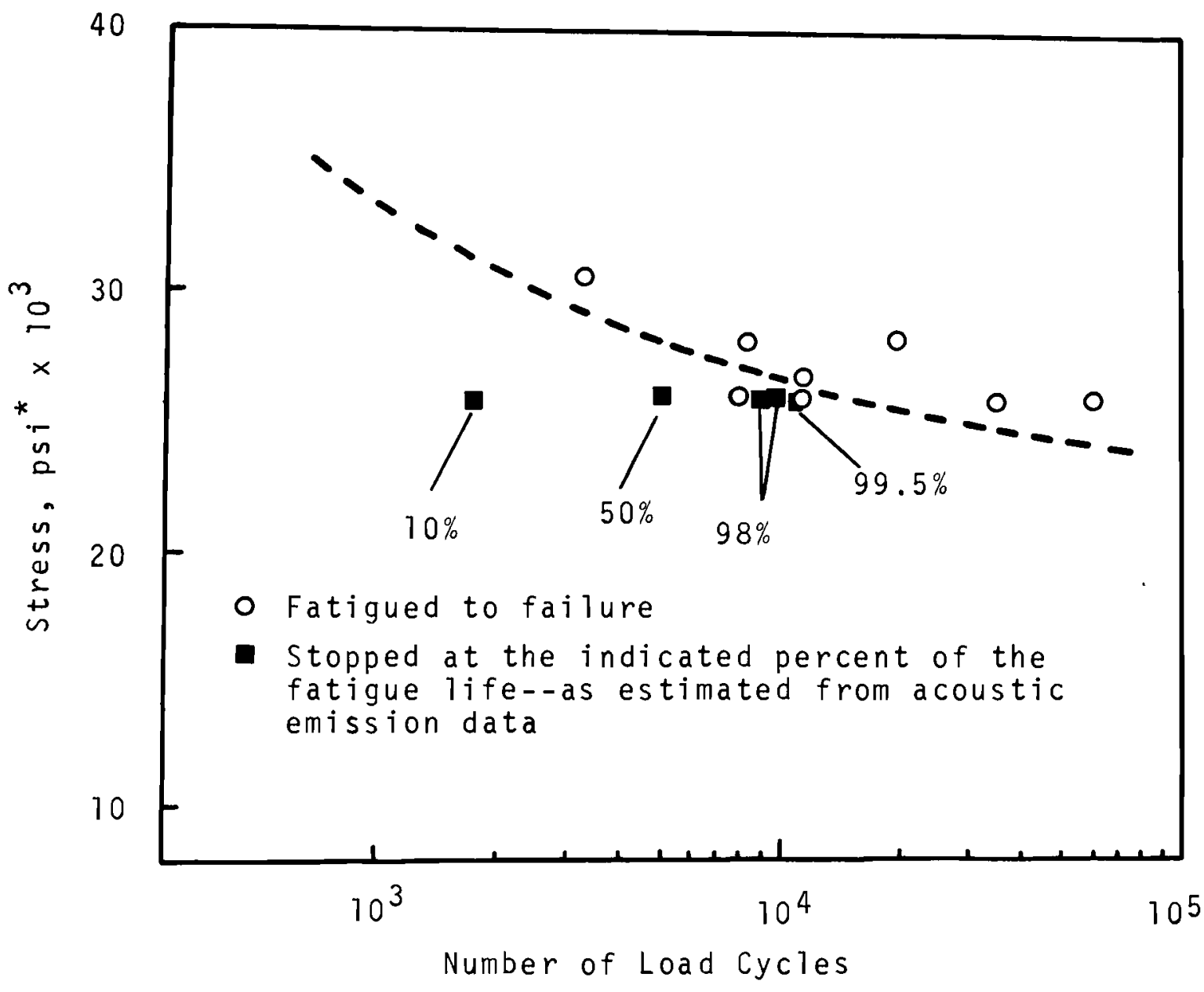

* Stress estimation based upon an assumed endurance limit of 23,000 psi.(2)

FIGURE 8. Flexure Fatigue Characteristics of Zircaloy-2 

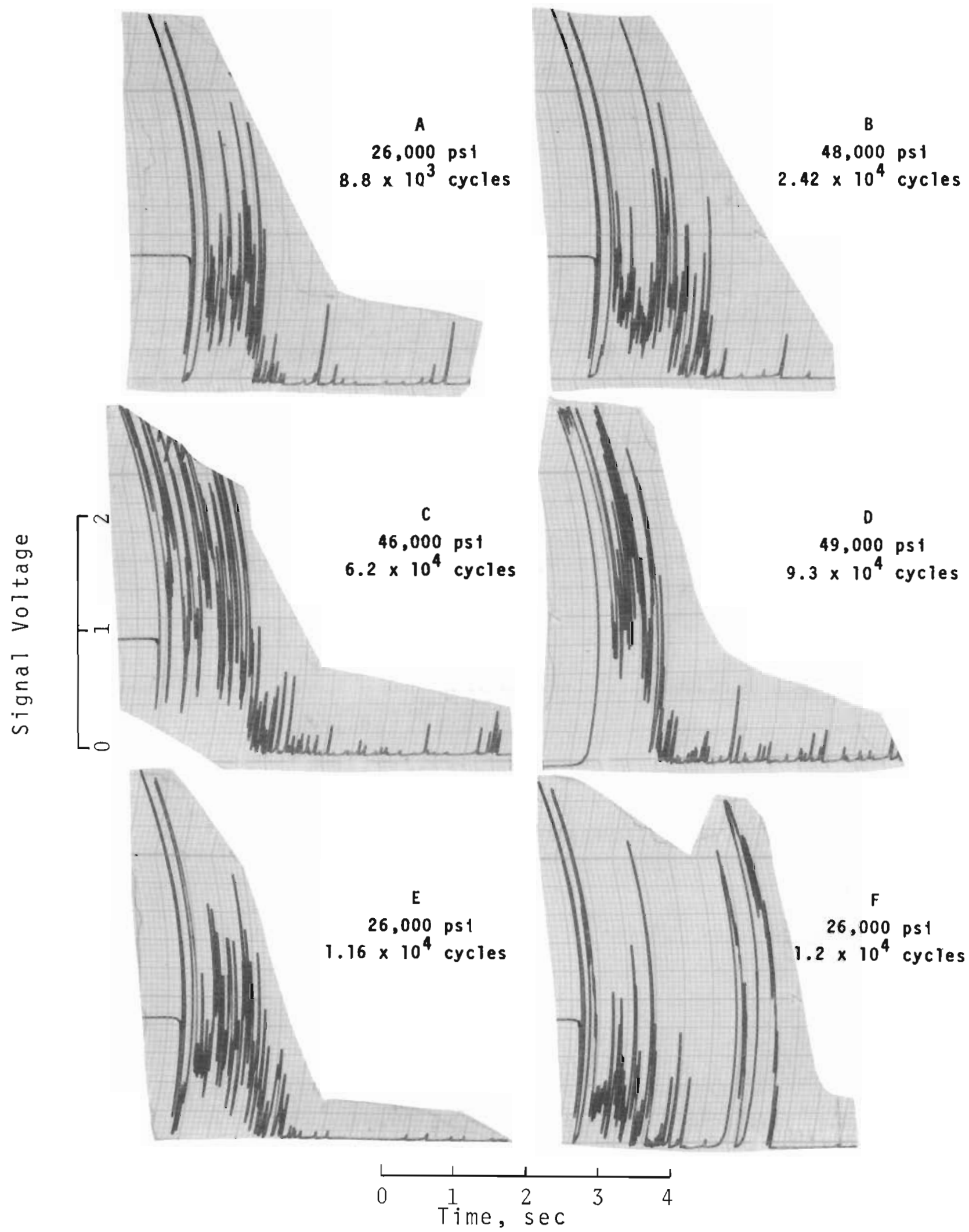

FIGURE 9. Increase in Acoustic Emission Response of Zircaloy-2 Immediately Prior to Fatigue Failure 
the fatigue life of the specimen. Another specimen was fatigued to the point at which the build-up of acoustic emission was first detected and the test was then stopped. This corresponds to approximately $98 \%$ of the fatigue life of the specimen. Still other specimens were fatigued at $26,000 \mathrm{psi}$ to an estimated 50 and $10 \%$ of their fatigue lives.

Actual data traces from a strip chart recorder, as received from this last series of fatigue tests conducted at $26,000 \mathrm{psi}$ and $30 \mathrm{cps}$, are shown in Figure 10. The top pair of traces is from a specimen fatigued completely to failure. The next pair is from a sample fatigued to $99.5 \%$ of its 1 ife and so on down for 98,50 , and $10 \%$ fatigue 1 ife values. There is some variation in the signal gain for the tests.

These specimens were then examined metallographically to follow the progress of fatigue damage as displayed in Figures 11 and 12 .

Two illuminations were used at a magnification of $250 \mathrm{X}$. Bright field illumination was used to emphasize the appearance of the crack, and polarized light illumination was used to emphasize the microstructural effects. The crack is shown to be clearly visible starting at $50 \%$ of the fatigue life. The crack growth rate appeared low up to $98 \%$ of the fatigue life and appeared high between 98 and $99.5 \%$ of the fatigue life. The extent of twinning is demonstrated best by the polarized light photomicrographs of Figure 12. In going from 10 to $98 \%$ of the fatigue life, the twin density increases very substantially. The twin density is greatest in the grains adjacent to the crack front in the specimen stopped at $98 \%$ of its fatigue life. Very little twinning, except for deformation twins in the grains adjacent to the machined notch, was seen in the untested specimen.

The acoustic emission characteristics are summarized in Figures 13 and 14 for the fatigue tests conducted. Figure 13 
Percent of Fatigue Life at Which Test was Stopped
Sensitivity
a. $2 \mathrm{~V} / \mathrm{cm}$
b. $0.2 \mathrm{~V} / \mathrm{cm}$

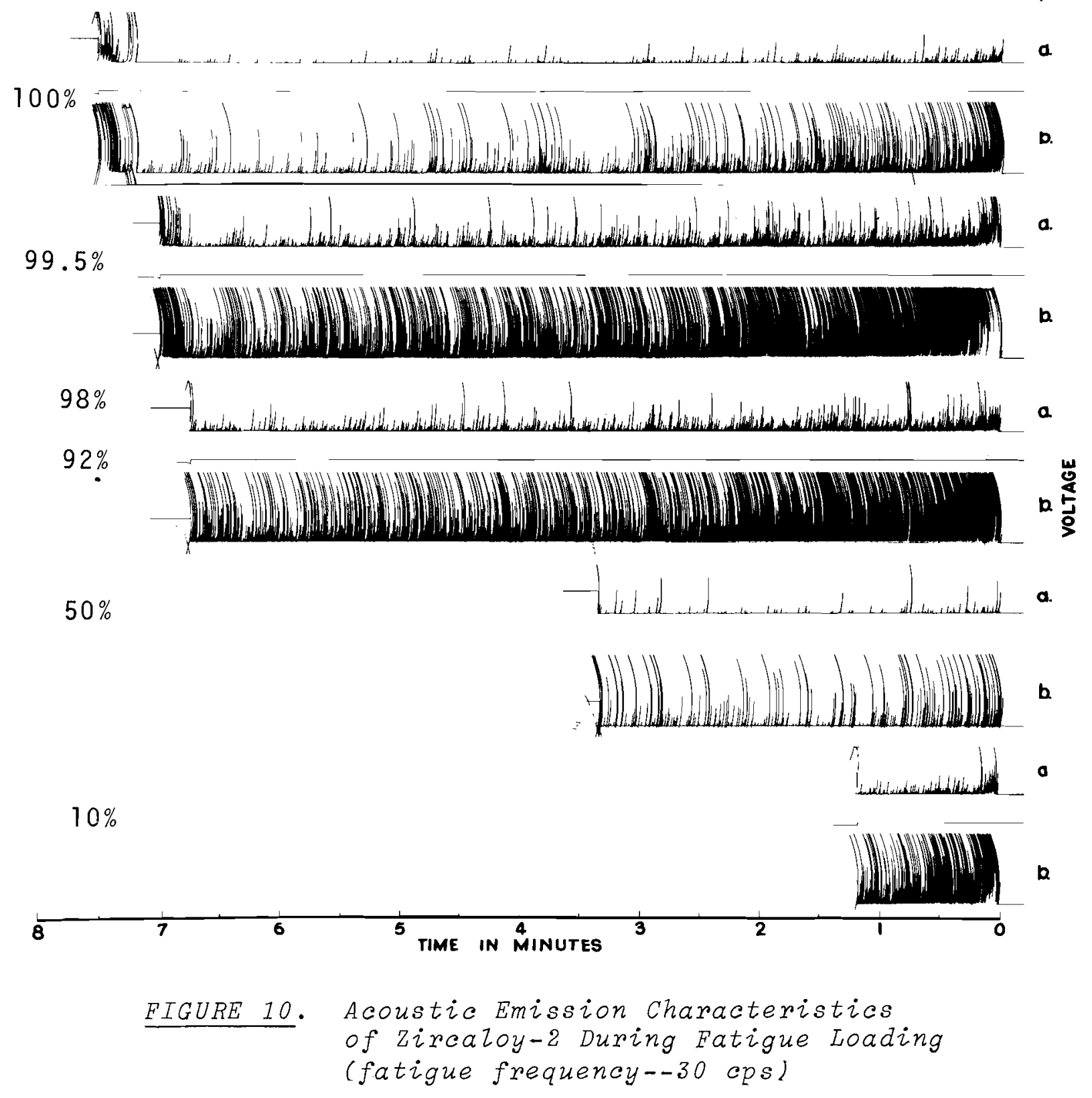


Percent of Fatigue Life at Which Test was Stopped

$99.5 \%$
A

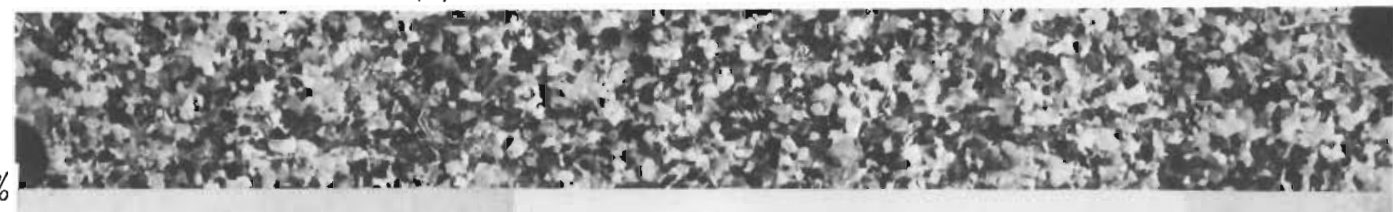

B

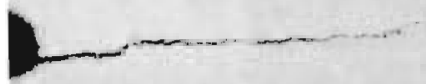

A

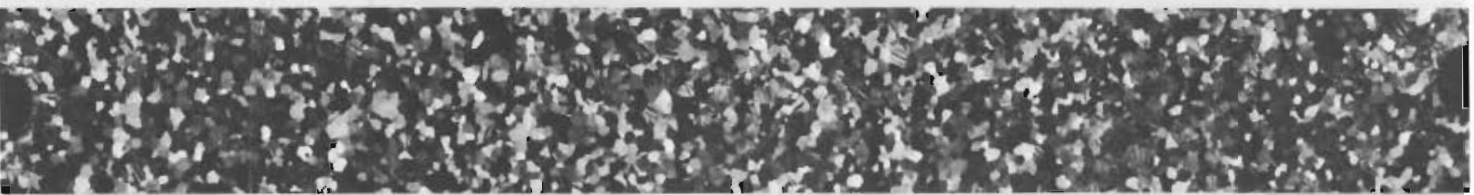

B<smiles>C1C[Te]C1</smiles>

$\mathbf{A}$

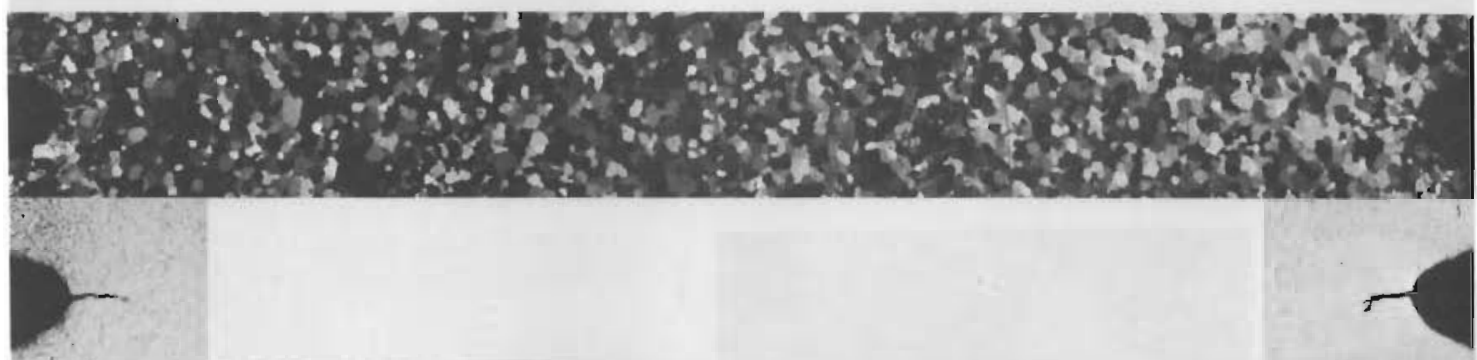

A

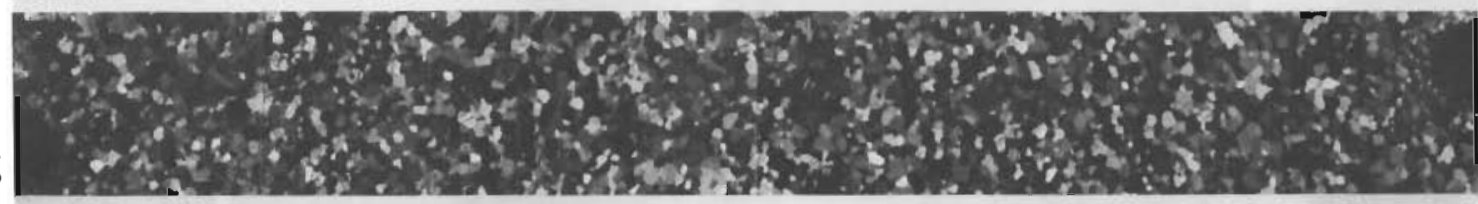

$10 \%$

B

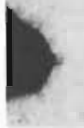

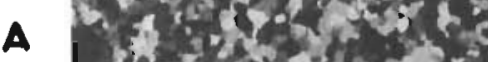

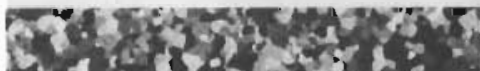

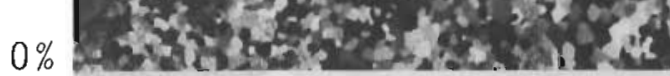

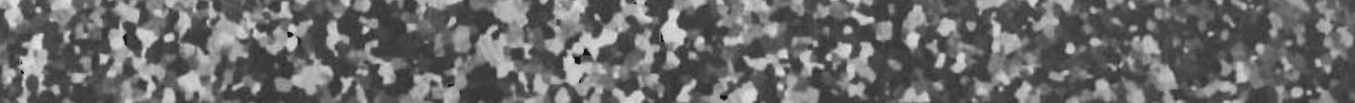

B

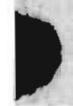

A--Polarized Light

B--Bright Field

$250 x$

EIGURE 11. Metallography of Zircaloy-2 from Notched section of Fatigue Specimens After Fatigue Loading 
Percent of Fatigue Life

at Which Test was Stopped

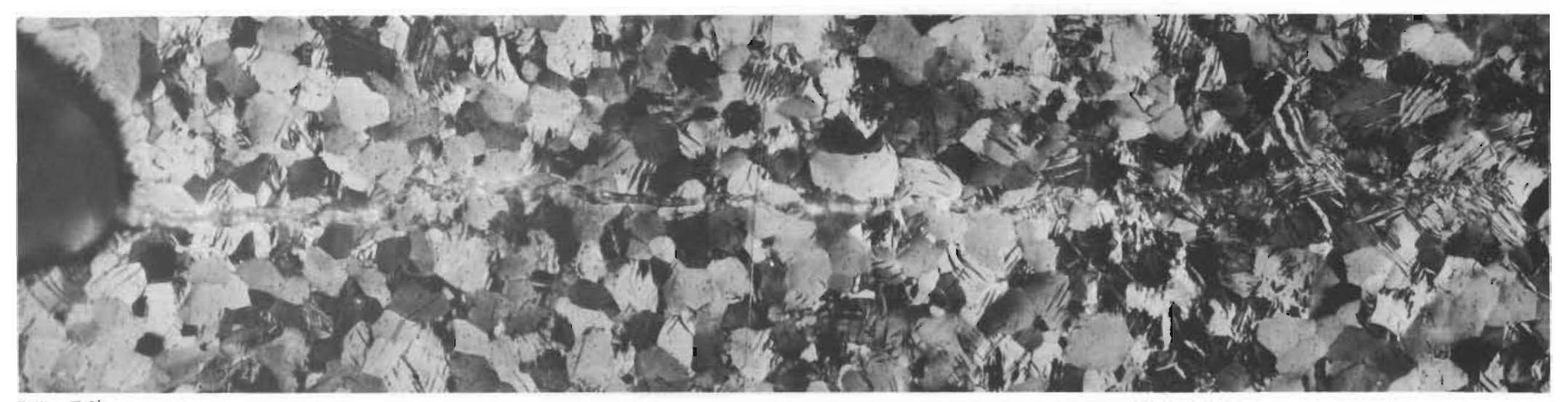

$99.5 \%$

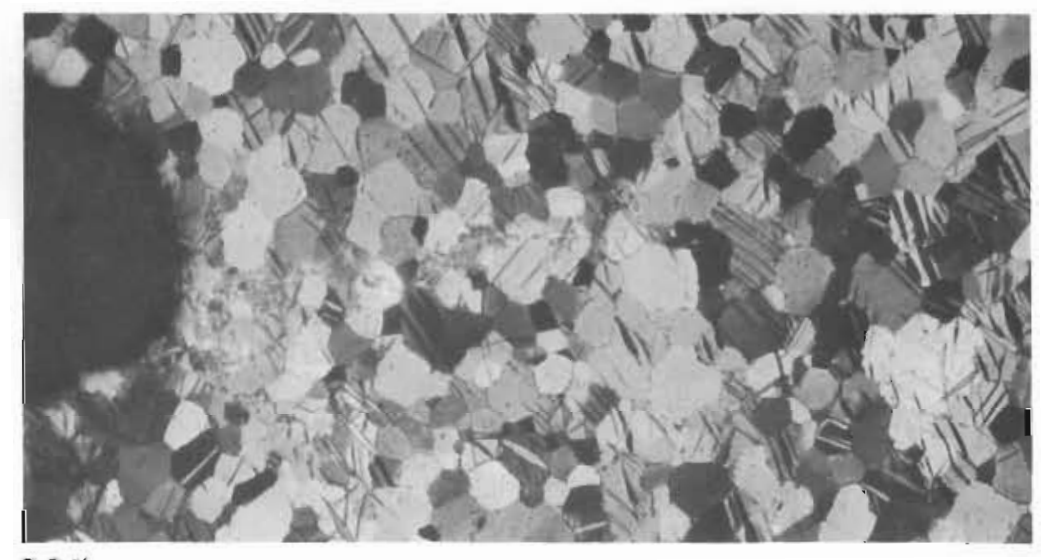

$98 \%$

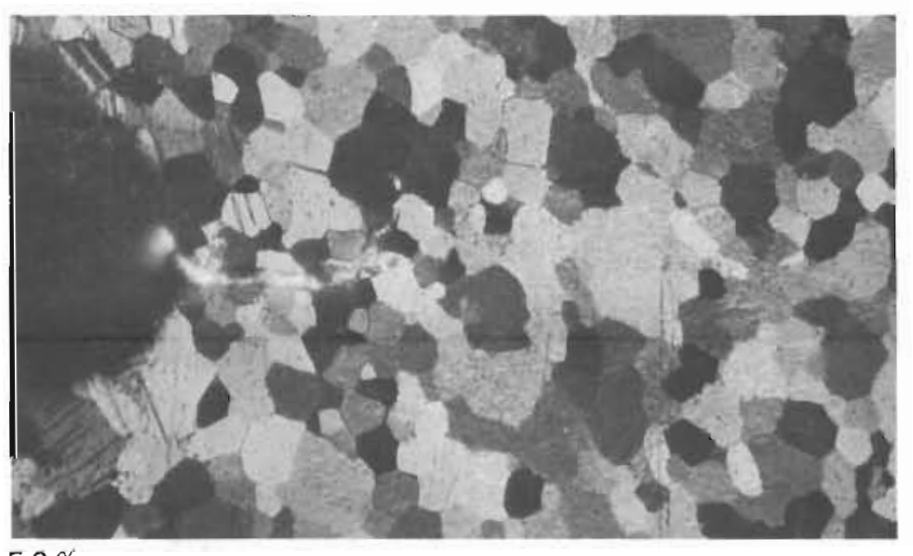

$50 \%$

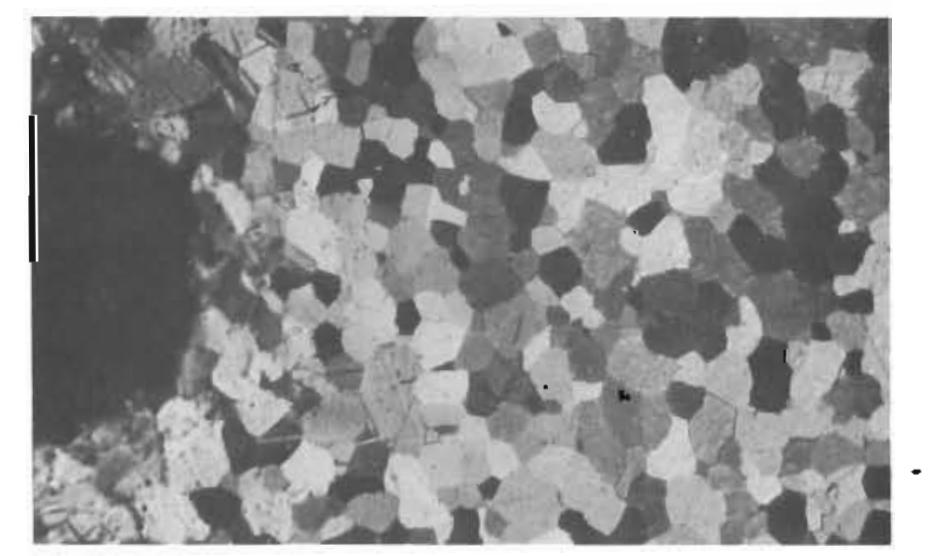

$10 \%$

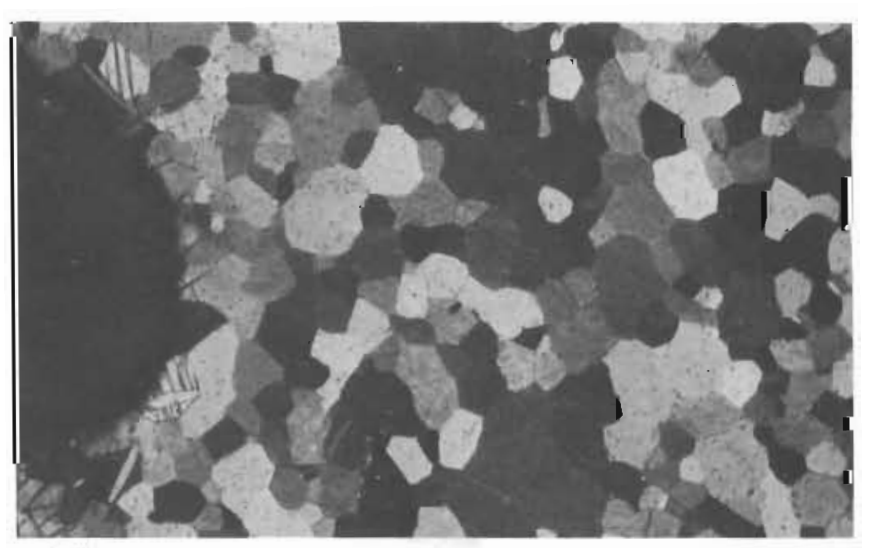



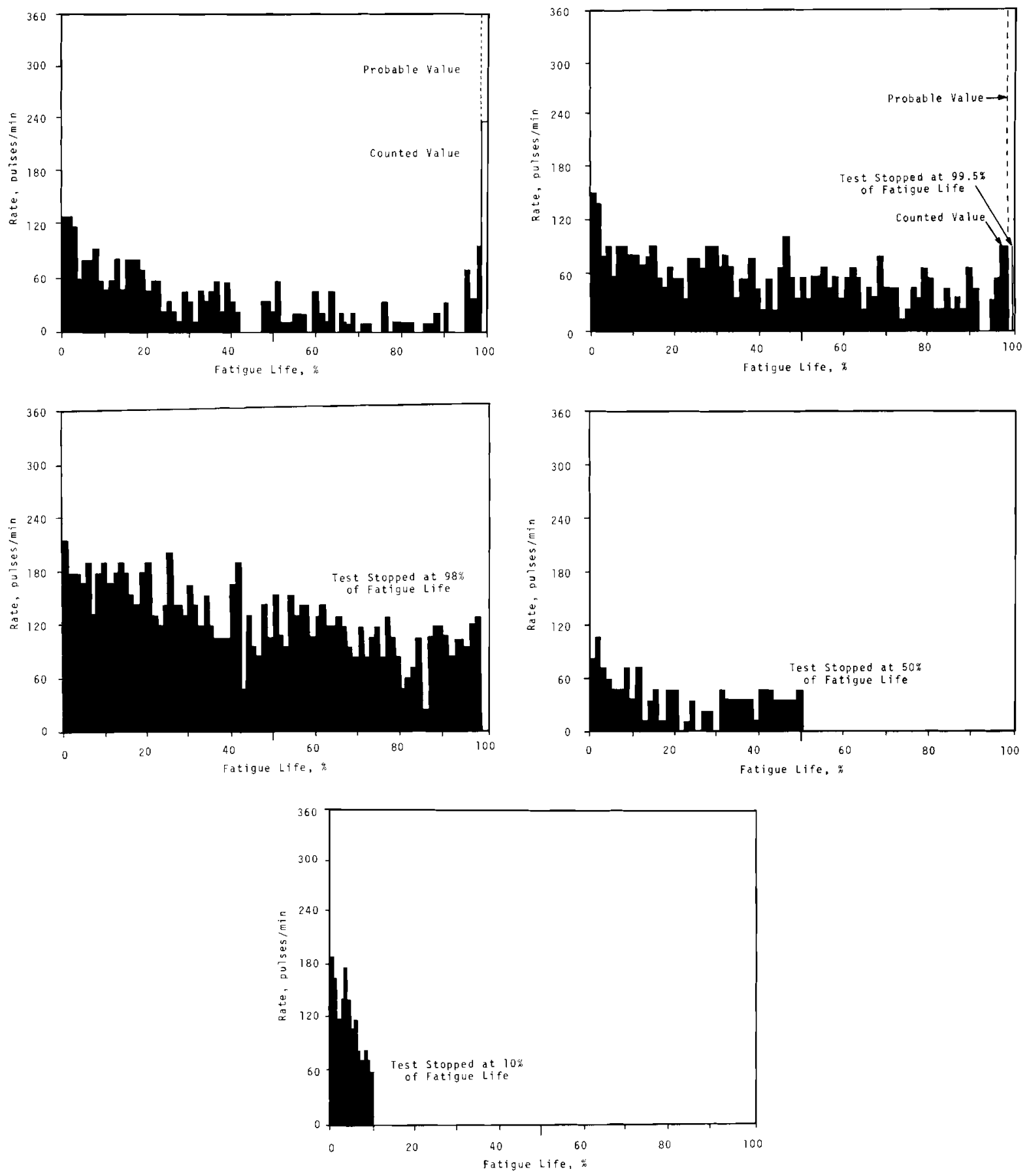

FIGURE 13. Acoustic Emission Pulse Rate Variation with Fatigue Life for Zircaloy-2 (fatigue frequency--30 cps) 
represents the number of pulses per second $\frac{d n}{d t}$. Figure 14 represents the total signal voltage per unit time $\frac{d v}{d t}$. The pulse rate and the signal voltage received per unit time were obtained manually by counting pulses over 0.1 volts on the strip chart records. During periods of high signal density, many pulses become obscured due to overlap on the recorder chart. The net result was that the counted values of $\frac{d n}{d t}$ and $\frac{d v}{d t}$ were much lower than their exact values during periods of high signal density. In Figures 13 and 14 , the manually counted values become questionable in the last $2 \%$ of the fatigue life due to high signal density during the final build up before failure. For this reason, a test was conducted with a pulse rate counter applied to the acoustic emission output in order to estimate the amount of error involved in the manual pulse rate count during the signal build-up before failure. Al1 pulses over $0.1 \mathrm{~V}$ and displaced in time by more than $100 \mu \mathrm{sec}$ were registered distinctly. The pulse rate received indicated the error to be in excess of an order of magnitude during this period of high signal density. The pulse rate leading to this build-up did, however, compare favorably to the manually counted values. The pulse rate and total voltage rate curves in Figures 13 and 14 thus are solidly filled in for the first $98 \%$ of the fatigue life. The constancy of this final build-up has been demonstrated (Figure 9) and, in light of this constancy, a probable pulse rate curve has been dashed in on Figure 13. The graphs are intended to show qualitatively the pulse rate variation with specimen fatigue life for the flexure fatigue of Zircaloy-2.

The mean amplitude of signals received from test to test was hard to control. The signal amplitude is a function of specimen loading, specimen characteristics, transducer coupling, and electronic instrumentation gain. Many of the tests, therefore, appeared to show different overall gains. A good example 

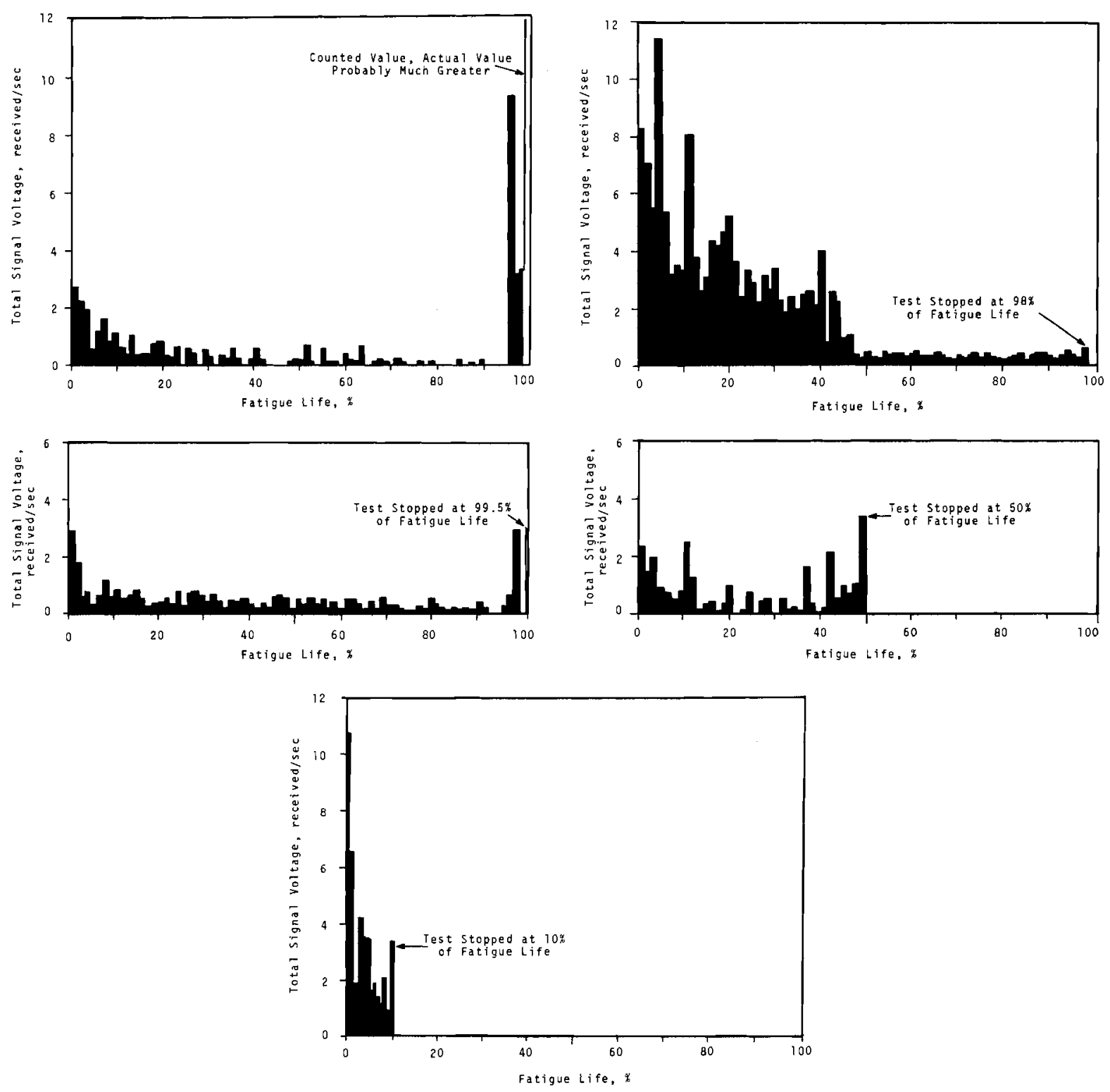

FIGURE 14. Acoustic Emission Total Signal Voltage Rate Variation with Fatigue Life for Zircaloy-2 (fatigue frequency--30 cps) 
of this difference is the $50 \%$ test shown in Figure 10 for which the gain appears less than the gain in any of the other tests. TENSILE TEST ANALYSIS

The acoustic emission response for these tensile tests has been represented in this report as a function of unit engineering strain rather than as function of unit time. The number of pulses per unit of strain has more significance for these tests than the number of pulses per unit time because the tests were conducted in a loading situation for which the strain rate was not constant.

Results of the acoustic emission monitoring of Zircaloy-2 tensile tests showed in both the number of pulses per unit of engineering strain, a pronounced peak before the $0.2 \%$ off-set yield point. Events associated with initial dislocation movement appear the most probable cause for the sharp drop in curves representing total pulse and voltage as macro yield begins. The hypothesis is that the majority of the information received in a tensile test of Zircaloy-2 is due to these events. Before the macro yield point, some dislocations lightly pinned in preferentially oriented grains are able to break away from their barriers and thus give rise to acoustic emission upon the application of very low stresses. The number of such dislocations breaking away will increase as the applied stress increases up to the macro yield point. Events occurring after macro yield can be attributed to dislocations breaking away from stronger pinning points in less favorably oriented grains within the plastic zone and to extension of the plastic zone out of the gage section of the specimen. The later two effects after macro yield should decrease with increasing stress. The acoustic emission response of the specimen thus should decrease as the ultimate strength is approached. The acoustic emission behavior during load recycling can be explained by the decrease 
in the number of dislocations freed with increasing cycles to the same stress amplitude. Thus, the acoustic emission response should decrease with each stress cycle upon recycling to a prior stress level. Upon reloading to a stress above a previously high stress level, the amount of plastic strain increases dramatically. Therefore, the number of dislocation depinning events should increase with a corresponding increase in the acoustic emission response. Experimental evidence supports this conclusion (Figure 6).

\section{FATIGUE TEST ANALYSIS}

In the fatigue tests, a loading frequency of 30 cycles/sec was used to provide much more acoustic emission information per second than could be obtained from tensile tests. To prevent signal saturation, the monitoring system gain had to be decreased $13 \mathrm{~dB}$ from the setting used in monitoring the tensile tests.

In analyzing the fatigue test results, it is useful to recall the effect of load cycling on the tensile test results. Cyclic tensile loading results suggest acoustic emission response to be maximum at the start of the test and to decrease with an increase in the number of load cycles. This expectation has been confirmed and, within the first 10 to $25 \%$ of the fatigue 1 ife, the acoustic emission response decreases to and remains near a stable value until failure is approached. The work of Gough has shown that a metal deforms under cyclic strains by slip on the same atomic planes and in the same crystallographic directions as in the unidirectional strain case of a tensile test. (3) The difference is that slip is widespread in the unidirectional strain case whereas, in fatigue, slip lines are not apparent in all the grains. This finding indicates that the major slip processes are confined to the more favorably oriented grains during fatigue. Slip lines produced during fatigue are usually visible after a few thousand load 
cycles. Their density usually approaches a constant value after $10 \%$ of the fatigue life in most cases. $(4,5)$ The fact that the acoustic emission response and the slip band density both approach a constant value after approximately $10 \%$ of the fatigue life further supports the hypothesis that much of the signal is caused by the initiation of dislocation movements.

As the fatigue process continues, slip line forms intrusions and extrusions on a microscopic scale and usually define the start of the fatigue crack which is generally transgranular. A detailed view of the notch on several specimens in Figure 11 shows the progress of the fatigue crack. Note that the crack is first visible between 10 and $50 \%$ of the fatigue 1 ife as observed here. The crack growth appears to be very gradual up until the last $2 \%$ of the fatigue life.

The twinning processes are expected to produce a very substantial report when they occur. Twinning events are audible to the ear in some metallurgical systems as "tin crying," twinning in zinc single crystals, etc. The formation rate of twin bands was observed to be uniform up to $98 \%$ of the fatigue 1ife. In the last $2 \%$ of the fatigue life, a great deal of twinning was seen to occur, particularly in grain adjacent to the crack tip (Figure 12). The last $2 \%$ of the fatigue life was also characterized by a dramatic build-up in the acoustic emission response (Figure 15). Figure 9 shows the constancy from test to test that lasted approximately $10 \mathrm{sec}$ prior to failure. Because of the change in twin band density observed during the 10 sec prior to the failure portion of the fatigue test, some of the signal in this final build-up can most certainly be attributed to twinning. A great deal of this signal might also be due to opening and closing of the crack tip and to propagation of the crack. A fluctuating plastic zone will move through the specimen ahead of the crack tip as the crack transverses the 


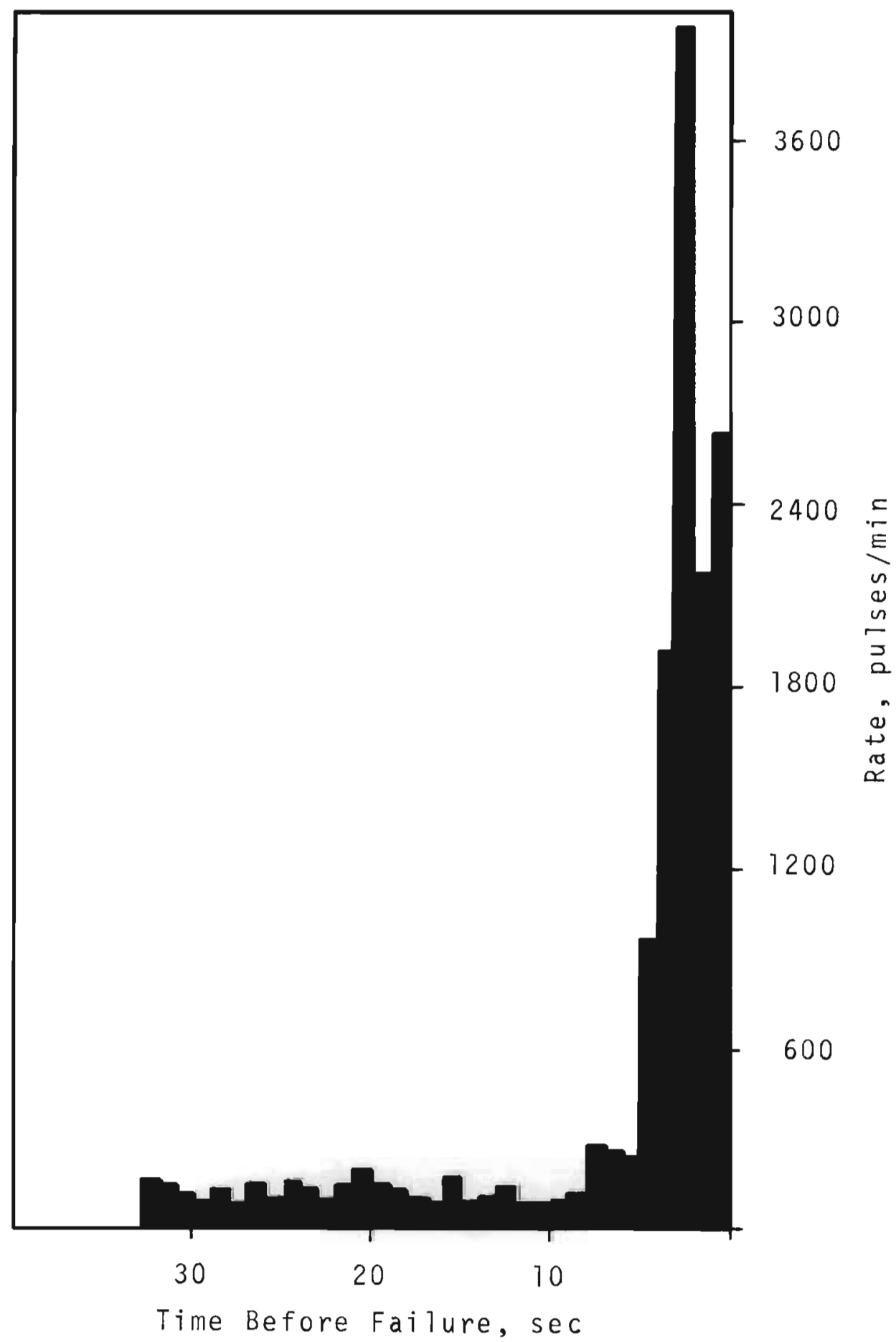

FIGURE 15. Increase in Acoustic Emission Pulse Rate Before Acoustic Failure 
sample. Dislocation movement initiated in this plastic zone should also contribute to the signal observed in the final build-up before failure. An oscilloscope trace made during the build-up prior to failure shows no periodic relationship between the majority of the information and the loading frequency (Figure 16). This observation indicates sources other than crack tip noise as responsible for the build-up and is relatable to deformation processes occurring with crack propagation.

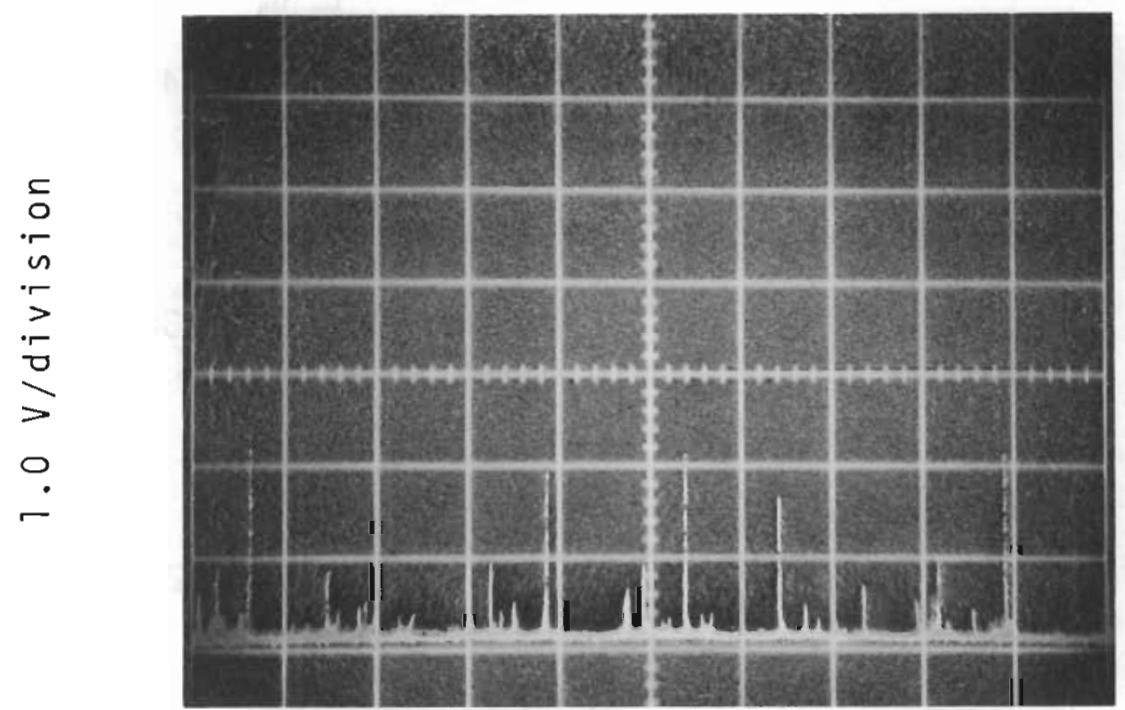

$10 \mathrm{mi} 11$ isec/division

EIGURE 16. Oscilloscope Trace of Signal Build-up Prior to Fatigue Faizure

\section{ACKNOWLEDGEMENTS}

The experimental assistance of R. E. Page and R. M. Ferdinand in conducting this study is gratefully acknow edged. The assistance of G. M. Everett and T. R. Rouse in data reduction was also appreciated. 


\section{REFERENCES}

1. T. E. Michaels and M. C. Fraser. Acoustic Emission Behavior of Zircaloy-2 Pressure Tubing Under Applied Stress, BNWL-545. Pacific Northwest Laboratory, Richland, Washington, September, 1967 .

2. W. J. O'DonneZZ and B. F. Langer. Fatigue Design Basis for Zircaloy Components, "Nuclear Science and Engineering," vol. 20, pp.1-12.1964.

3. H.J. Gough, "Proc. ASTM," vol. 33, pt. 2, pp. 3-114. 1933.

4. D. MeLean. Mechanical Properties of Metals, John Wiley \& Son, Inc., New York, 1962.

5. R. E. Reed-Hizz. Physical MetalZurgy Principals, University Series in Basic Engineering. Van Nostrand Company, Inc., Princeton, New Jersey, 1964 . 


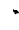

.

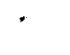

- 


\section{DISTRIBUTION}

No. of

Copies

1

AEC Canoga Park

Canoga Park, California

RDT Site Office

2

AEC Chicago Patent Group

Chicago, Illinois

G. H. Lee

R. K. Sharp

AEC Division of Technical Information Extension

AEC, Germantown, Pennsylvania

DRDT, Technical Advisory Committee

N. E. Todreas, Office of Reactor Engineering

R. Feit, Office of Plant Engineering

R. M. Scroggins, Office of Reactor Technology

S. Strauch, Office of Program Analysis

A. Van Echo, Office of Reactor Technology

R. A. Anderson, Assistant General Counse1 for Patents

9

AEC Library, washington, D.C.

Division of Reactor Development Technology

Chief, HWOCR Branch (3)

Chief, Core Design Branch

Chief, Fuel Fabrication Branch

Chief, Control Mechanisms Branch

Assistant Director, Reactor Technology

Chief, Fuels and Materials Branch

Chief, Special Technology Branch

AEC, RDT Site Representatives - PNL

P. G. Holsted (2)

A. S. Waterhouse

AEC Richland Operations Office

C. L. Robinson

Technical Information Library 
No. of

Copies

4

Atomic Energy of Canada Limited

Toronto, Canada

E. C. W. Perryman

J. A. L. Robertson

P. A. Ross

W. R. Thomas

2

Babcock and Wilcox

Lynchburg, Virginia

4

M. W. Croft

L. B. Gross

Battelle Memorial Institute

T. J. Atterbury

1

Boeing Company

Renton, Washington

R. Davis, Metals and Standards

1

Carolina-Nuclear Power Association

Parr, South Carolina

W. N. Thomas

3

Combustion Engineering, Inc.

Windsor, Connecticut

R. P. Varnes

1 Combustion Engineering, Inc.

Windsor, Connecticut

RDT Site office

2 Donald Douglas Laboratories

Richland, Washington

M. Smith

Douglas United Nuclear Corporation

W. K. Alexander

T. W. Ambrose

R. Cooperstein

D. H. Curtiss

File 
No. of

Copies

1

duPont Company, Savannah River

Aiken, South Carolina

RDT Site Representative

3

duPont Company, Savannah River

Aiken, South Carolina

S. W. O'Rear (2)

D. F。Babcock

3

1

2

1

1

7

56

\section{Lawrence Radiation Laboratory}

Livermore, California

J。Hadley

H. Dunegan

C. Tatro

Naval Research Laboratory

L. Steele

United Kingdom Atomic Energy Authority

Reactor Group, Reactor Materials Laboratory Wigshaw Lane, Culcheth, Lancashire, England

R. Nichols

B。Watkins

USAEC, Scientific Representative

Chalk River, Ontario Canada

R. W. Ramsey, Jr.

USAEC, Technical Representative

Whiteshel1 Branch, Manitoba, Canada

$\mathrm{H} 。 \mathrm{~J}$ 。 Reynolds

Washington State University

Pullman, Washington

G. E, Duva11, Department of Physics

T.E. Michaels, Department of Physics (5)

R. F, Tinder, Department of Metallurgy

Batte1le-Northwest

F。W.Albaugh

W. G. Albert

W. E. Anderson

R. C, Aungst

J.M. Batch 
Battelle-Northwest (contd)

C. A. Burgess

K. O. Creek

P. D. Cohn

G. M. Dalen

S. M. Gill

H. Harty

B. R. Hayward

R. J. Jackson

R. N. Johnson

W. C. Kinse 1

R. L. Knecht

W. R. Lewis

R. J. Lobsinger

R. P. Marsha11

T. R. Osburn

P. J. Pankaskie

R. H. Purce 11

W. E. Roake

E. B. Schwenk, Jr.

J. C. Spanner

J. L. Straalsund

J. C. Tobin

L. D. Turner

P. C. Walkup

R. G. Wheeler (10)

D. C. Worlton

Technical Information Files (5)

Technical Publications (2) 